YING-EN GE

E-mail: yege@shmtu.edu.cn

1. College of Transport and Communications

Shanghai Maritime University, China

2. School of Transportation and Logistics

Dalian University of Technology, China

OLEGAS PRENTKOVSKIS

E-mail: olegas.prentkovskis@vgtu.It

Department of Transport Technological Equipment

Vilnius Gediminas Technical University, Lithuania

CHUNYAN TANG

E-mail: tang21106282@163.com

School of Transportation and Logistics

Dalian University of Technology, China

WAFAA SALEH

E-mail:w.saleh@napier.ac.uk

Transport Research Institute

Edinburgh Napier University, United Kingdom

MICHAEL G. H. BELL

E-mail: michael.bell@sydney.edu.au

Institute of Transport and Logistics

University of Sydney Business School, Australia

RAIMUNDAS JUNEVIČIUS

E-mail: raimundas.junevicius@vgtu.It

Department of Transport Technological Equipment

Vilnius Gediminas Technical University, Lithuania
Traffic Planning

Review

Submitted: Feb. 1, 2015

Approved: Nov. 24, 2015

\title{
SOLVING TRAFFIC CONGESTION FROM THE DEMAND SIDE
}

\section{ABSTRACT}

It is nowadays widely accepted that solving traffic congestion from the demand side is more important and more feasible than offering more capacity or facilities for transportation. Following a brief overview of evolution of the concept of Travel Demand Management, there is a discussion on the Travel Demand Management foundations that include demand-side strategies, traveller choice and application settings and the new dimensions that Active Forms of Transportation and Demand Management bring to Travel Demand Management, i.e. active management and integrative management. Subsequently, the paper provides a short review of the state-of-the-art of Travel Demand Management focusing on relevant literature published since 2000 . Next, we highlight five relevant topics that are currently hot: traffic congestion pricing, public transit and bicycles, travel behaviour, travel plans and methodology. The paper closes with some concluding remarks.

\section{KEY WORDS}

travel demand management; traffic congestion pricing; travel behaviour; travel plans; active demand management; integrative demand management;

\section{INTRODUCTION}

As intercity traffic is becoming faster with an increasing mileage of motorways and high-speed railways, urban traffic is becoming slower, which causes additional costs to the global economy, risen transport costs, increased fuel consumption and deteriorating transport pollution. Worsening urban congestion is the result of many factors, including increased travel demand for intensified economic and leisure activities and growing population. After many decades of experience in traffic and transportation engineering, it has become widely acknowledged that strategies to manage demand are more important to transport operations than strategies to increase capacity (supply) of facilities and that better use needs to be made of existing and new transport infrastructure. The inability to easily and quickly add new or expand the existing infrastructure in keeping up with the growth in passenger and freight transport has resulted in the need to pay more attention to Travel Demand Management (TDM).

The concepts of TDM are rooted in efforts of the 1970s and 1980s and aimed at offering alternatives to single occupancy commuter travel for the sake of energy savings, environmental improvement and con- 
gestion alleviation. A few decades later, the scope of TDM evolved to cover both commuter and non-commuter travel during recurrent and non-recurrent congestion, which has a much broader scope than just moving commuters from their private cars to public transit or ridesharing [1]. Recently, Active forms of Transportation and Demand Management (ATDM) have been investigated in the US [2] with an aim to manage, control and influence travel demand, traffic and transportation facilities in real time.

There is no generally accepted definition of TDM because its scope continues to evolve. Section 2 briefly investigates the foundations of TDM plus a review of the latest progress in TDM based on the literature published since 2000. Section 3 highlights five TDM topics that are currently hot: traffic congestion charging; public transit and bicycles; traveller behaviour; travel plans plus methodology. Last section concludes the paper with some remarks.

\section{FOUNDATIONS OF TRAVEL DEMAND MANAGEMENT}

TDM is part of Transport System Management (TSM). Essentially, it is a series of strategies used by experts to manage transport demand, in order to meet the town-residents' needs for mobility and to provide the desired lifestyles and development within a town itself. In the early 1980s TDM first appeared in the cities of the US as a response to the culmination of the problems with traffic congestion and the negative effects generated by traffic (air pollution, irrational use of traffic infrastructure, time loss, increased number of traffic accidents, etc.). The term "travel demand management" originated in South California in 1985. In the mid-1980s the TDM approach began to be implemented in Europe. The first articles on TDM were published in professional journals at the beginning of the 1990s [3].

This section first describes three core elements of TDM and then looks at new dimensions in ATDM. It also includes a review of the latest progress in TDM based on the literature published since 2000.

\subsection{Three core elements of travel demand management}

As pointed out in [1], "A variety of demand-side strategies are implemented in order to impact the travel choices of individuals and organizations, in the context of a wide array of application settings". In this statement, "demand-side strategies", "travel choices" and "application settings" are considered the three core elements of TDM.

\section{Demand-side strategies}

According to [1] such strategies can be divided into "general" and "targeted" ones. General strategies in- clude technology accelerators (e.g. traveller information), travel time incentives (e.g. High Occupancy Vehicle (HOV), High Occupancy Toll (HOT) lanes), financial incentives (e.g. congestion pricing), marketing and education (e.g. social/individualized marketing), etc. Complementing broader-based general demand-side strategies, targeted strategies focus on traveller choices regarding mode, departure time, trip route, and choice to travel and location. Contrary to the targeted TDM strategy, a general TDM strategy can affect the full range of traveller choices, from mode choice to residential or work location choice.

Demand-side strategies are "designed and implemented by organizations with a role to play in mitigating traffic congestion, including state/regional/local governments, employers, special event managers, and many others" [1]. To formulate the most efficient and effective mix of travel choices, organizations need to frequently tailor their TDM recipes composed of both general and targeted strategies.

Travel choices

Travellers choose their travel modes, departure times, and travel routes, decide whether to travel and more fundamentally, where to live and/or work. Modes travellers may choose among "drive alone", carpool or vanpool, transit, non-motorized vehicles, etc. In terms of route choices, the travellers may choose alternative roadway routes or mode routes. These choices are the "key travel choices made by individuals and organizations that collectively impact the efficiency and performance of the transportation system" [1] and the use of policy, regulations, information, finance, technology and other assets and facilities to form sustainable travel choice behaviour is the essence of TDM.

\section{Application settings}

To guarantee the performance of a TDM strategy, it is normally tailored to a wide range of different application settings so that it can address targeted trip types or travel market segments, such as schools, special events (e.g. World Cup), recreation and tourism destinations, transportation corridor planning and construction mitigation, employer-based commuter programs, airports, incidents and emergencies, freight transportation, etc.

\subsection{New dimensions in active forms of transportation and demand management}

By means of available instruments and assets ATDM manages traffic flow and influences traveller behaviour in real time so that operational objectives can be achieved, including "preventing or delaying breakdown conditions, improving safety, promoting sustainable travel modes, reducing emissions, or maximizing system efficiency" [2]. It is worth pointing out that ATDM introduces two more dimensions that the 
conventional TDM does not cover, i.e. active management and integrative management.

As sensors and detector equipment are increasingly smart, a richer and continuous set of data on time-varying traffic states and travel behaviour is available, which defines a big data set for transportation and demand management. While monitoring the entire transportation system continuously, optimal actions are selected based on this big data set and performed in real-time to improve system performance.

Under an ATDM approach, available tools and assets are utilized to dynamically manage, control and influence travel choices, traffic and facilities in an integrative framework. The conception of integrative management creates a strategic commitment with the support of technology and existing assets and programs to actively manage transportation, including demand management, traffic management, parking management and efficient utilization of other transportation modes and assets. These approaches complement each other in an integrative framework.

By means of the aforementioned two new dimensions and on the basis of existing capabilities, assets and programs, ATDM enables agencies to leverage the existing investments so that a more efficient and effective system is achieved and the service life of existing capital investments is extended. Given these, all agencies and entities operating transportation systems can develop a more active management philosophy.

In the past decade, a great interest in introducing Voluntary Travel Behaviour Change (VTBC) initiatives for TDM emerged [4-5]. The Weekly No-Driving Day program implemented in Seoul, Korea, requires that voluntary participants select days on which to refrain from car use. Ko and Cho analyse the effectiveness of this program [5].

\subsection{State-of-the-art of travel demand management: a short review}

As it has evolved in the US, the origin of TDM is related to federal policy initiatives that first focused on improving the efficiency of urban transportation systems through operational improvements, and then incorporated concerns such as air quality and energy conservation [6]. This short review of the state-ofthe-art of TDM focuses on the literature in this field published since 2000 and the readers interested in a review of TDM before 2000 may refer to [6-7].

"Time and financial incentives are most effective" is the second from the ten lessons which are summarized from case studies on TDM in [1]. These strategies include time savings for alternative mode users (such as HOV/HOT lanes), financial incentives (such as vanpool subsidies or tax incentives) and financial disincentives (such as parking or road and congestion pricing). Parking and congestion charging are probably the most common strategies among all TDM strategies based on time and financial incentives that have been implemented. Kaufman et al. [8] provided a review of contemporary approaches to parking pricing, including technology and organizations involved and case studies. Button [9] looked into ways in which economists view parking charges within the context of policy formulation and Kelly and Clinch [10] investigated the impacts of varied parking tariffs on parking occupancy levels by trip purpose. Either parking or congestion charging has potential effects on travel behaviour. The work on traffic congestion charging can be generally divided into two categories: designing optimal congestion charging schemes [11-14] and evaluating and/or solving/overcoming derived problems of the existing congestion charging schemes [15].

There is a large amount of research on fiscal policy instruments for reduction in transport externalities, the key part of which includes congestion and transport emissions. It has been found that congestion charging may achieve 9-12\% reduction of vehicular traffic and a significant improvement in environmental quality. Considering long-term dynamics and uncertainty of transportation demand, Nagae and Akamatsu [16] proposed a prototype dynamic revenue management method for a private toll road

"Packaging demand-side strategies can create synergies" is the seventh lesson from the ten summarized from case studies of TDM in [1]. Gärling and Schuitema [17] reviewed "research addressing the question of how effective, acceptable to the public, and politically feasible ... [TDM] measures are". The consistent findings are presented in [1], stating that "non-coercive TDM measures alone are unlikely to be effective in reducing car use". To increase the political feasibility and gain the public support, there is a need for an effective, acceptable, and politically feasible way to combine coercive TDM measures (e.g. increasing the cost for car use or prohibiting the use) with non-coercive TDM measures (e.g. offering attractive travel alternatives and communicating the benefits of car-use reduction to the public). The role of TDM policy interactions may take place at the macro or micro level. Hendricks [18] reviewed "four primary challenges to incorporating TDM into the land development process: (a) the idea that TDM is valuable only if it can reduce travel; (b) transportation professionals considering TDM too late in the land development process; (c) the conflict between state and local governments for providing the balance between mobility and access; (d) the use of traffic analysis methods and standards that are geared toward preserving highway Level Of Service (LOS) for motor vehicles", and concluded that "TDM strategies are positioned poorly, internally to government leaders and partner departments and externally to land developers as a sort of mobility 'diet' imposed on the traveling public". 
To develop an effective TDM strategy, it is essential to have a good tool for assessing a strategy, which involves at least two items: a set of comprehensive metrics and a way to capture the distribution of traffic or travel demand within a targeted area at a chosen time scale (short-, medium- or long-term). It has been challenging to find comprehensive metrics applicable to all transportation programs. Finke and Schreffler [19] discussed the state-of-the-practice in TDM evaluation and pointed out that generally the evaluation of the effectiveness of a TDM project aims to understand: the ability to get information to travellers to lead them to more sustainable trip chains (including modes, departure times, activities, etc.) and the impacts of trip chain changing on travel and air quality. "The former type of evaluation is sometimes called soft evaluation (awareness of services offered, inquiries for information, etc.), and the latter is called hard evaluation (trip, vehicle miles of travel, and emission reduction)".

To evaluate TDM alternatives, a Multi-Criteria Decision Making (MCDM) based methodology may be required and takes into account not merely quantitative criteria (i.e. transportation and environmental impacts) but also qualitative criteria (i.e. social impacts); these criteria are intrinsically uncertain and subjective. It is noteworthy that citizens' perception (subjective) of a TDM strategy may be very different from that of the experts, especially in performance evaluation. Jou et al. [20] investigated the level of satisfaction regarding the existing TDM strategies for road users in Taipei as well as the level of acceptance of not yet implemented ones and found that "disincentive strategies, also known as 'sticks', could solve the problems of traffic jams, but their acceptance or satisfaction is lower than their feeling of effectiveness of TDM strategies". This reference also acknowledged that "shortening the travel time of mass transportation tools is an important factor to increase travellers' willingness to use them". The use of HOV/HOT lanes to mitigate traffic congestion and its associated environmental problems receives an ever-increasing attention. If HOV/HOT lanes are specially designated for private cars and promotion of carpooling, bus lanes are for HOV transportation but only for public transit (and in some cities for taxis as well). Different than conventional bus lanes, a contra-flow bus lane runs in the opposite direction of private car traffic flow. When more people are willing to accept carpooling behaviour, the utilization of HOV/ HOT lanes will rise. Carpooling represents one of many possible alternatives to Single-Occupancy Vehicle (SOV) use for work or school trips. To encourage carpooling, web-based applications have been developed to facilitate connections between potential carpoolers. The investigation in [21] of this example suggests that "spatial accessibility to matches, household auto ownership, and socio-demographics influence carpooling more than do proximity to carpool infrastructure and personal attitudes (e.g., concern for the environment, cost)". With respect to policy and planning, [21] suggested that "increasing shared knowledge about commuting patterns at the home end of work trips could yield beneficial returns to the carpool formation and use process".

Nowadays, the majority of tours consist of more than one activity and may also involve more than one transport mode. A trip chain consists of all activities and modes involved within one tour. A solid understanding of trip chaining behaviour may significantly improve the degree to which a TDM project succeeds in achieving its goals. Wallace et al. [22] investigated the relative effect that each of a wide variety of factors has on the extent to which a traveller will chain trips, by means of a negative binomial regression model, in which the number of trips in a chain is assumed to depend on household characteristics, traveller characteristics, trip characteristics and urban form. It has been found that some of the variables representing TDM strategies can increase the level of trip chaining whereas others may decrease the level of chaining.

To address car parking and traffic congestion problems in a high-density commercial and residential district, Portland implemented a plan composed of a number of elements targeted at curbing SOV use for commuting to/from the district, which included paid parking in the form of meters (where on-street parking had been free), discounted transit passes, and other TDM strategies. The effects of these strategies on travel and parking behaviour were assessed in [23], with an emphasis on the relationship between parking pricing and mode choice. It was found that, during the first year that elapsed between the implementation of this plan and collection of the survey information, the drive-alone mode for commuting by employees in the district decreased by $7 \%$.

To address the journey to work [24] investigated 20 case studies of UK employers undertaking travel planning, who have cut commute driving by an average of $18 \%$. The investigation concluded that considerable behavioural change could be achieved in a variety of contexts; however, employers usually need an overall strategy that addresses car parking as well as improving alternative travel modes. Moreover, a more comprehensive national strategy is needed if travel planning is to achieve its potential. Mongioi et al. [25] explored "how Metropolitan Planning Organizations (MPOs), as coordinators of regional transportation decision making, can promote regional business continuity after an emergency" so that employee mobility and business continuity can be ensured by means of TDM strategies. This reference "highlights best practices including public-private partnerships, resource-sharing protocols, and technology applications" and "lessons learned, and planning and coordination efforts aimed at supporting employee mobility after an emergency". 
To seek low-carbon transport systems, [26] reviewed a series of potential ways, including behavioural options, demand reduction, innovative technologies, pricing, standards, regulations, etc. From a long-term perspective, it is a good idea to integrate TDM into transportation and/or land use planning processes. In April 2008, a comprehensive survey of TDM programs in the US was carried out by the Texas Transportation Institute, which tended to obtain empirical evidence for the performance of carpool programs, vanpool programs, guaranteed ride home, employer outreach, regional marketing, etc. [27].

\section{CURRENT HOT TOPICS ON TRAVEL DEMAND MANAGEMENT}

As already known, TDM is the application of strategies, policies and technologies to reduce travel demand (specifically that of single-occupancy private vehicles), or to redistribute this demand in space and/ or in time. In transport, as in other networks, managing demand can be a cost-effective alternative to increasing capacity. Specifically in the transport area, this approach also has the potential to deliver better environmental outcomes, improve public health, develop stronger communities and more prosperous and livable cities. TDM techniques link with and support sustainable transport for a smart community.

Managing both the "growth of" and periodic "shifts in" travel demand is essential for traffic congestion mitigation. If travel demand is not managed, the performance of a transportation system would be negatively affected. Managing demand can no longer stop at encouraging travellers to change their travel mode from driving alone to a carpool, vanpool, public transit vehicle, or other commuter alternatives but moves towards providing all travellers, regardless of whether they drive alone or not, with choices of work/home location, route, time as well as mode [28].

Today, the concept of TDM takes on a broader set of transportation goals due to the greater need to manage demand in multiple situations and conditions as well as the ever-increasing capability of data collection and information dissemination and the ever-rich technologies to deliver it. A more contemporary model of TDM may be illustrated as in Table 1 [28], which enables us to address a series of non-conventional issues.

This section highlights the following five TDM topics that are currently hot around the world: (a) traffic congestion charging; (b) public transit or bicycles; (c) traveller behaviour; (d) travel plans; and (e) methodology. There may be hundreds of papers or more on each topic. It is not our purpose to review all relevant papers but point out a couple of key issues for each of these hot topics.
Table 1 - Contemporary model of Travel Demand Management

\begin{tabular}{|c|c|}
\hline \multicolumn{2}{|c|}{ TRAVEL DEMAND MANAGEMENT } \\
\hline \multicolumn{2}{|c|}{$\begin{array}{l}\text { Objectives: } \\
\text { - to improve reliability; } \\
\text { - to create effective choices }\end{array}$} \\
\hline $\begin{array}{c}\text { Commute Travel } \\
\text { (getting to work/home) }\end{array}$ & $\begin{array}{c}\text { Non-Commute Travel } \\
\text { (tourism, special events, } \\
\text { emergencies, construction, etc.) }\end{array}$ \\
\hline $\begin{array}{l}\text { - Accessibility } \\
\text { - Predictability } \\
\text { - Information } \\
\text { - Choice } \\
\text { - System performance }\end{array}$ & $\begin{array}{l}\text { - Accessibility } \\
\text { - Reliability } \\
\text { - Information } \\
\text { - Choice } \\
\text { - System performance }\end{array}$ \\
\hline
\end{tabular}

\subsection{Traffic Congestion Charging}

Road traffic congestion pricing was proposed as early as in the 1920s to internalize external costs drivers produce but do not bear by themselves [29]. Singapore implemented the world's first congestion charging project in 1975. Since then much effort has been put into design and evaluation of congestion charging schemes.

Traffic congestion constantly increases and has brought huge economic loss to most of the megacities such as Beijing (China), Delhi (India), Jakarta (Indonesia), Karachi (Pakistan), Lagos (Nigeria), Mexico City (Mexico), Mumbai (India), New York (United States), Osaka (Japan), Sao Paulo (Brazil), Seoul (South Korea), Shanghai (China) and Tokyo (Japan) - as of 2014, there are 33 megacities in existence - each of these has a population in excess of 20 million inhabitants. Liu et al. [30] forecast traffic impacts under the condition of implementing congestion charging in the old central district of Beijing (China). This reference measured the travel conditions under congestion charging based on TDM models and proposed a set of suggestions of implementing congestion charging.

Ye [31] reviewed the practice of congestion charging in Singapore and London and suggested that traffic congestion charging should take scientific plan, public support, public transportation development as the premise. While reducing traffic externalities the existing traffic congestion charging projects implemented around the world have brought out a series of concerning issues, including equity and boundary effects. The boundary effects exist in a temporal and spatial manner. The temporal boundary effect of congestion charging refers to the fact that travellers depart earlier or later than the charging period to avoid paying full or part of the congestion charging tolls, which creates undesired demand peaks that correspond to the sharp rises or drops of the toll and are often greater than available capacity. The spatial boundary effect generated by congestion charging refers to the fact 
that travellers would rather stay away from a charging zone than pay congestion charging tolls, which causes undesired congestion on those roads or paths on the edge of the charging zone. These efforts in [15] show that congestion charging may not be able to eliminate hyper-congestion efficiently if schemes are not well-designed, and can unfortunately give rise to undesired boundary effects and that a simply-designed congestion charging scheme with small level toll or time-varying toll profiles can reduce the magnitude of boundary effects but may not be able to eliminate fully such undesired effects.

The equity issue incurred by congestion charging is at least two-dimensional. One is the conventional social equity issue between poor and rich drivers who pay the same toll charge and the other is a spatial equity issue in the sense that the changes in the generalized travel costs of drivers travelling between different OD pairs may vary significantly when a second-best pricing scheme is implemented. Eliasson and Mattsson [32] develop a method for detailed and quantitative assessment of equity effects of road pricing and apply it to a proposed congestion-charging scheme for Stockholm. It is found that if revenues are used for improving public transport (or for tax cuts), this would be of most benefit to women and low-income groups (or high-income groups). Given that it is likely that the revenues would be used to some extent to improve the public transport system, the proposed congestion-charging scheme for Stockholm was considered to be progressive rather than regressive. Karlström and Franklin [33] considered specifically two behavioural adjustments: mode choice and departure time choice and assessed the horizontal and vertical equity effects of the Stockholm Trial with Congestion Pricing for morning commuters, in terms of both travel behavioural adjustments and welfare effects. The existing practice has implied significant opportunities for financing new roadway investment while addressing congestion and equity issues, with net gains for both types of travellers.

By explicitly incorporating the social and spatial equity constraints in terms of the maximum relative increase of the generalized equilibrium OD travel costs between all OD pairs for various classes of drivers with different values of time, [34] proposed bi-level programming models for network toll design. Wu et al. [35] developed a modelling framework that considers the effect of income on travellers' choices of trip generation, mode and route on multimodal transportation networks and explicitly captures the distributional impacts of congestion-mitigation policies on different income and geographic groups.

Traffic congestion on motorways is also a concern. As a freeway TDM strategy, HOT lanes have been deployed to manage traffic on HOV lanes. To ensure the successful operation of HOT lanes, it is essential to periodically adjust the toll in response to the temporal variation in demand. It is widely acknowledged, however, that this task is complicated by heterogeneity of traveller willingness to pay and uncertainties in time-varying traffic conditions. Taking into account these factors Jang et al. [36] proposed an algorithm to determine the optimal toll level aiming to minimize the total delay borne by both HOVs and low-occupancy vehicles.

\subsection{Public transit or bicycles}

The customer perception of the public transport service level has been an important issue in cases where such services aim to reduce SOV travel demand. Grujičić et al. [37] showed that public transport customers perceived the level of service as an indicator of transport system quality and proposed a method for identifying those elements that affect the perceived service level of public transport.

As more cities introduce public bicycle schemes, the investigation of public bicycle operations and management (including the infrastructure for them) has received an ever-increasing attention. A great deal of work has been contributed to describe the use of a new public bicycle share program in Montreal (Canada) [38], discuss certain impacts of this program on cycling, potential modal shift and health benefits, plus likelihood of collisions and near misses, and review the impact on the provision of bicycle facilities (pathways, bikeways and parking) of planning policies that promote utilitarian cycling and was concerned with the impact of public transportation strikes on use of a bicycle share program in London. Stewart and McHale [39] explored the characteristics of cycle lanes and their effects on driver passing distances in urban areas.

In considering the interests of both users and investors, [40] proposed a model to determine the number and locations of bike stations, the network structure of bike paths connecting stations, and travel paths for users between each OD pair. To support decision-making in the design and management of public bicycle-sharing systems, [41] developed a network flow model with proportionality constraints to estimate the flow of bicycles within the network and the number of trips supported, given an initial allocation of bicycles at each station. They also examined the effectiveness of periodic redistribution of bicycles in the network to support greater flow, and the impact on the number of docks needed.

To address the long- and steady-decreasing trend in bicycle use in the past two decades in China, governments at nearly all levels created various Public Transit Priority schemes to encourage public transport initiatives. As part of this effort, the government of the city of Hangzhou launched the Hangzhou Public Bicycle Scheme in 2008. Based on the data collected in Hangzhou, such factors as accessibility of 
bike stations, real-time bike, parking availability, bike maintenance and locking mechanisms, and extending operational hours have been identified as significant factors that lead to bike-sharing adoption and barriers to adoption [42].

In response to those transport-related challenges in the environmental, economic, and social dimensions, such sustainable alternatives to SOV modes as walking, cycling, and public transit, either as single modes or in combination have been promoted. The marriage between cycling and transit particularly presents opportunities for synergy by enlarging catchment areas of transit stations while drawing in new users to both of these green modes. To overcome the difficulty arising from the marginality of this "marriage" and, accordingly, a shortage of reliable empirical studies in this area, [43] addressed this gap through an analysis of travel behaviour and preferences related to CycleTransit (C-T) integration. This investigation shows that bringing a bicycle into transit was the preferred form of integration; however, scenarios involving bicycle parking (or using a public bicycle) were likely to be used more regularly, and that, to accommodate the largest number of bicycle transit trips, measures should be taken to facilitate cycle parking at transit stops and enable bicycles to be taken on the bus or train (either under- or over-ground carriages).

\subsection{Traveller behaviour}

The essence of TDM is the management of traveller choice, whose success relies on a comprehensive understanding of traveller behaviour. The existing distributional pattern of travel demand is to a great extent determined by effects of travel behaviour on choices of workplace, residential location, vehicle type, departure time, trip mode, route, etc. Choocharukul et al. [44] empirically investigated psychological effects of travel behaviour on residential location choice by commuters and found that preference regarding residential location was significantly affected by behavioural intention towards car usage. Several socio-economic variables and psychological images regarding modes of transport were investigated in [44]. Respondents' gender and current residential location were found to be among the main factors that significantly linked to future residential preference. Furthermore, some psychological aspects towards modes of transport were found to be important determinants for respondents' choice of future residential area.

By means of a survey measuring situational and psychological factors of significant importance for the next car purchase, the impacts of adapting current taxation measures to incentivize Low-Emission Vehicle (LEV) purchase and the potential role of a range of taxation measures on their decisions on the type of future car purchase, [45] identified population seg- ments according to their psychological preparedness and importance attached to situational factors in their future decisions to purchase a LEV. Al-Atawi and Saleh [46] find that travel decisions are usually influenced by accessibility as well as characteristics of the transport systems or, as shown in [37], by service quality perception. As a popular TDM policy that can reduce commute travel volume during the AM and PM peak periods, and relieve traffic congestion, a staggered shifts program may be able to effectively influence commute travel behaviour.

\subsection{Travel plan}

As a TDM tool, a typical travel plan is composed of a package of measures that interact to change the means of travel. The success of a travel plan depends on a variety of factors, such as land use policy.

Evaluations carried out in many countries show that soft policy measures in the form of personalized travel planning reduce private car use and increase travel by public transport. None of the evaluations of the documented programs met the method requirements for such evaluations as regards design and effect measurement. Additionally, reporting was substandard as well as non-standard in the way that is desirable in order to enable comparative analyses. With reservations for these shortcomings, it is inferred in [47] that positive effects on a par with the results elsewhere have been obtained in some of the implemented programs. It is however necessary to conduct higher quality evaluations. Vanoutrive [48] proposed workplace-oriented tools for travel plans for building projects, mandatory travel plans, subsidies to employers with an advanced travel plan and best travel plan awards; in all cases, experts judged the level of car use. School children travel plans to school/home were investigated in [49], which raises and discusses important issues identified during a literature review, documentary analysis, and an empirical evaluation of school travel plans. Quantitative and qualitative data were collected using questionnaires, travel diaries and interviews. The output measures were - "levels of walking to and from school" and "awareness and attitudes" towards initiatives. Characteristic workplace-oriented tools involved in transport planning include travel plans for building projects, mandatory travel plans, subsidies to employers with an advanced travel plan and best travel plan awards.

\subsection{Methodology}

Since the 1970s a series of TDM strategies have been implemented across the world. It is difficult to find a tool for evaluating short-term, medium-term and long-term effects of a potential TDM strategy. Among those offering such tools, [50] proposed a multi-agent based Q-learning algorithm to evaluate the effects of 
staggered working hours, which simulated travellers' behaviour of temporal and spatial choices in their activity-travel patterns. Ko et al. [51] offered a method for evaluating the efficiency of the current Radio-Frequency IDentification (RFID) systems that are implemented to ensure the effectiveness of a Weekly No-driving Day (WND) programme introduced in Seoul, South Korea, in 2003.

In empirical analysis, the regression analysis, or its variants, is still a technique used most. To extract origins and destinations, search for matched trips, etc. for data collection, the GIS technique is necessary to complete this task. Based on 176 samples from two cities in Thailand, structural equations were used in [44] to analyse psychological effects of travel behaviour on commuters' residential location choice.

Dynamic Traffic Assignment (DTA) models (including bottleneck models) are an essential tool for analysing the spatio-temporal effects of a TDM scheme, as shown in [15]. However, the DTA modelling assumptions born from the static case limit the use of resulting DTA models because, for example, User Equilibrium (UE) requires that all used paths between an OD pair have minimized and identical generalized travel costs. In reality, due to imperfect traveller information on prevailing and predictive traffic conditions plus the tolerance in travellers' choice behaviour, a UE state may never appear but a non-UE state may stay stable [52].

\section{CONCLUDING REMARKS}

To ensure that the economic success is not hindered by traffic congestion and that the improvement in living conditions is not clouded by transport pollution, it is now widely accepted that solving traffic congestion from the demand side is more important and more feasible than offering more capacity or facilities of transportation.

Over the years, the scope of TDM has evolved from focusing on moving travellers from SOV to other alternatives to a much broader spectrum of measures aiming at "providing travellers, regardless of whether they drive alone or not, with informed choices of travel route, time, and location" [1]. The foundation of TDM includes demand-side strategies, traveller choice and application settings; the appearance of Active Forms of Transportation and Demand Management brings active management and integrative management into the TDM arena.

A comprehensive review of all literature on TDM is not our original goal. Our intention is to point out five TDM topics: traffic congestion charging; public transit or bicycles; traveller behaviour; travel plans; and methodology. For congestion charging, we discussed two issues: equity and boundary effects. The equity issue is reviewed briefly from two aspects: social and spatial dimensions. The former is often due to the difference in household income while the latter is attributed to spatial distribution of effects of congestion pricing. Regarding public transit or bicycles, our focus is on the use and impacts of bike-sharing programs plus the use of bikes to compensate for the last-mile gap in public transit services. The discussion on traveller behaviour paid attention to the effects of travel behaviour on choices of workplace, residential location, vehicle type, departure time, trip mode, route, etc. among which the choice of residential location and car purchase were briefly reviewed. As for travel plans, we were concerned with those factors that may determine the success of a travel plan. Finally, it was acknowledged that a variety of techniques have been used to design, evaluate and re-design various TDM strategies or measures or actions; however, we still face the shortage of efficient and effective methodology for implementing TDM with exact prescription of the goals of a TDM project that can be achieved with great certainty.

\section{REFERENCES}

[1] Luten K, Binning K, Driver D, Hall T, Schreffler E, Anderson S, Chung F, Gray J, Schor J, Ungemah D, Widby $\mathrm{T}$, Wisco T. Mitigating traffic congestion - the role of demand-side strategies. Publication No.: FHWAHOP-05-001, U.S. Department of Transportation Federal Highway Administration. 114 p.; 2004. Available from: http://www.ops.fhwa.dot.gov/publications/ mitig_traf_cong/mitig_traf_cong.pdf

[2] FHWA. ATDM program brief: an introduction to active transportation and demand management. Publication No.: FHWA-HOP-12-032, US Department of Transportation, Federal Highway Administration (FHWA), Washington, DC. 2 p.; 2012. Available from: http://ops. fhwa.dot.gov/publications/fhwahop12032

[3] Malić A, Brčić D, Krasić D. Parking measures in travel demand management. Promet - Traffic \& Transportation. 2000;12(5-6):301-309.

[4] Bonsall P. Do We know whether personal travel planning really works? Transport Policy. 2009;16(6):306314.

[5] Ko J, Cho Y. Voluntary program to reduce car use: weekly no-driving day in Seoul, South Korea. Transportation Research Record. 2009;(2118):1-7.

[6] Meyer MD. Demand management as an element of transportation policy: Using carrots and sticks to influence travel behavior. Transportation Research Part A. 1999;33(7-8):575-599.

[7] Ferguson E. Travel demand management and public policy. Aldershot: Ashgate Publishing Ltd.; 2000.

[8] Kaufman M, Formanack M, Gray J, Weinberger R. Contemporary approaches to parking pricing: a primer. Publication No.: FHWA-HOP-12-026, U.S. Department of Transportation Federal Highway Administration. 48 p.; 2012. Available from: http://www.ops.fhwa.dot. gov/publications/fhwahop12026/fhwahop12026.pdf

[9] Button K. The Political Economy of Parking Charges in "First" and "Second-Best" Worlds. Transport Policy. 2006;13(6):470-478. 
[10] Kelly JA, Clinch JP. Influence of varied parking tariffs on parking occupancy levels by trip purpose. Transport Policy. 2006;13(6):487-495.

[11] Zhang HM, Ge YE. Modeling variable demand equilibrium under second-best road pricing. Transportation Research Part B. 2004;38(8):733-749.

[12] Yao T, Friesz TL, Wei MM, Yin Y. Congestion derivatives for a traffic bottleneck. Transportation Research Part B. 2010;44(10):1149-1165.

[13] Yang $H$, Wang $X$. Managing network mobility with tradable credits. Transportation Research Part B. 2011;45(3):580-594.

[14] Xiao F, Shen W, Zhang HM. The morning commute under flat toll and tactical waiting. Transportation Research Part B. 2012;46(10):1346-1359.

[15] Ge YE, Stewart K, Sun B, Ban XG, Zhang S. Investigating undesired spatial and temporal boundary effects of congestion charging. Transportmetrica B: Transport Dynamics. 2014;1-23. doi:10.1080/21680566.2014 .961044.

[16] Nagae T, Akamatsu T. Dynamic revenue management of a toll road project under transportation demand uncertainty. Networks and Spatial Economics. 2006;6(34):345-357.

[17] Gärling T, Schuitema G. Travel demand management targeting reduced private car use: effectiveness, public acceptability and political feasibility. Journal of Social Issues. 2007;63(1):139-153.

[18] Hendricks SJ. Four challenges to incorporating transportation demand management into the land development process. Transportation Research Record. 2008;(2046):30-36.

[19] Finke T, Schreffler EN. 2004. Using multiple assessment levels for evaluating transportation demand management projects: monitoring and evaluation toolkit. Transportation Research Record. 2004;(1864):135143.

[20] Jou R-C, Chen C-C, Chen Y-L. The effects of travellers' acceptance/satisfaction of unimplemented/ implemented transportation demand management strategies on travel behavior. Transportmetrica. 2011;7(3):201-228.

[21] Buliung RN, Soltys K, Habel C, Lanyon R. Driving factors behind successful carpool formation and use. Transportation Research Record. 2009;(2118):31-38.

[22] Wallace B, Barnes J, Rutherford GS. Evaluating the effects of traveler and trip characteristics on trip chaining, with implications for transportation demand management strategies. Transportation Research Record. 2000;(1718):97-106.

[23] Bianco MJ. Effective transportation demand management: combining parking pricing, transit incentives, and transportation management in a commercial district of Portland, Oregon. Transportation Research Record. 2000;(1711):46-54.

[24] Cairns S, Newson C, Davis A. Understanding successful workplace travel initiatives in the UK. Transportation Research Part A. 2010;44(7):473-494.

[25] Mongioi F, McNally L, Thompson R. Integrating measures for business continuity and transportation demand management to ensure regional emergency preparedness and mobility. Transportation Research Record. 2009;(2137):85-94.
[26] Banister D, Anderton K, Bonilla D, Givoni M, Schwanen T. Transportation and the Environment. Annual Review of Environment and Resources. 2011;36:247-270.

[27] Ungemah D, Dusza C. Transportation demand management benchmark: results from 2008 TDM program survey. Transportation Research Record. 2009;(2118):55-66.

[28] FHWA. Travel demand management. US Department of Transportation, Federal Highway Administration (FHWA), Washington DC; 2004. Available from: http:// www.ops.fhwa.dot.gov/tdm

[29] Knight FH. Some Fallacies in the interpretation of social cost. The Quarterly Journal of Economics. 1924;38(4):582-606.

[30] Liu Z, Li C, Li C. Traffic impact analysis of congestion charge in mega cities. Journal of Transportation Systems Engineering and Information Technology. 2009;9(6):57-62.

[31] Ye S. Research on urban road traffic congestion charging based on sustainable development. Physics Procedia. 2012;(24B):1567-1572.

[32] Eliasson J, Mattsson LG. Equity effects of congestion pricing: quantitative methodology and a case study for Stockholm. Transportation Research Part A. 2006;40(7):602-620.

[33] Karlström A, Franklin JP. Behavioral adjustments and equity effects of congestion pricing: analysis of morning commutes during the Stockholm trial. Transportation Research Part A. 2009;43(3):283-296.

[34] Yang H, Zhang XN. Multiclass network toll design problem with social and spatial equity constraints. Journal of Transportation Engineering. 2002;128(5):420-428.

[35] Wu D, Yin YF, Lawphongpanich S, Yang H. Design of more equitable congestion pricing and tradable credit schemes for multimodal transportation networks. Transportation Research Part B. 2012;46(9):12731287.

[36] Jang K, Oum S, Chan, CY. Traffic characteristics of high-occupancy vehicle facilities: comparison of contiguous and buffer-separated lanes. Transportation Research Record. 2012;2278:180-193.

[37] Grujičić D, Ivanović I, Jović J, Đorić V. Customer perception of service quality in public transport. Transport. 2014;29(3):285-295

[38] Fuller D, Gauvin L, Kestens Y, Daniel M, Fournier M, Morency P, Drouin L. Use of a new public bicycle share program in Montreal, Canada. American Journal of Preventive Medicine. 2011;41(1):80-83.

[39] Taylor \& Francis Newsroom. Do cycle lanes increase safety of cyclists from overtaking vehicles? October 2014, Oxford, UK.

[40] Lin J-R, Yang T-H. Strategic design of public bicycle sharing systems with service level constraints. Transportation Research Part E. 2011;47(2):284-294.

[41] Shu J, Chou MC, Liu Q, Teo C-P; Wang I-L. Models for effective deployment and redistribution of bicycles within public bicycle-sharing systems. Operations Research. 2013;61(6):1346-1359.

[42] Shaheen SA, Zhang H, Martin E, Guzman S. China's Hangzhou Public bicycle: understanding early adoption and behavioral response to bikesharing. Transportation Research Record. 2011;(2247):33-41. 
[43] Bachand-Marleau J, Larsen J, El-Geneidy AM. Much-anticipated marriage of cycling and transit: how will it work? Transportation Research Record. 2011;(2247):109-117.

[44] Choocharukul K, Van HT, Fujii S. Psychological effects of travel behavior on preference of residential location choice. Transportation Research Part A. 2008;42(1):116-124.

[45] Borthwick S, Carreno M. Exploring the potential for 'green' taxation measures to influence individuals' car purchasing decisions. Association for European Transport and Contributors; 2011. 20 p.

[46] Al-Atawi A, Saleh W. Tabuk Study Final Report. Technical Report. Edinburgh Napier University, Transport Research Institute, UK; 2013.

[47] Friman M, Larhult L, Gärling T. An analysis of soft transport policy measures implemented in Sweden to reduce private car use. Transportation. 2013;40(1):109-129.
[48] Vanoutrive T. Workplace travel plans: can they be evaluated effectively by experts? Transportation Planning and Technology. 2014;37(8):757-774.

[49] Baslington $H$. School travel plans: overcoming barriers to implementation. Transport Reviews. 2008;28(2):239-258.

[50] Yang M, Tang D, Ding H, Wang W, Luo T, Luo S. Evaluating staggered working hours using a multi-agent-based q-learning model. Transport. 2014;29(3):296-306.

[51] Ko J, Kim D, Sin HG, Lee S. The efficiency of vehicle monitoring locations for a voluntary travel demand management program. Transport. 2014;29(3):326333.

[52] Ge YE, Sun BR, Zhang HM, Szeto WY, Zhou X. A comparison of dynamic user optimal states with zero, fixed and variable tolerances. Networks and Spatial Economics. 2015;15(3):583-598. doi:10.1007/s11067014-9243-9. 